\title{
Observation of ionospheric disturbances induced by the 2011 Tohoku tsunami using far-field GPS data in Hawaii
}

\author{
Long Tang, Xiaohong Zhang ${ }^{*}$ and Zhe Li
}

\begin{abstract}
In this study, we employ far-field GPS total electron content (TEC) observed in Hawaii to detect the ionospheric disturbances induced by the 2011 Tohoku tsunami. We observed tsunami-driven traveling ionospheric disturbances (TIDs) at two different times: at about 12:40 UT, there were TIDs in the disturbance series propagating at approximately $260 \mathrm{~m} / \mathrm{s}$ in an outward direction from the tsunami's source, and then, the signals began to weaken and gradually disappeared after 14:00 UT; however, at about 17:30 UT, the TIDs appeared again in the disturbance series with similar propagation characteristics. According to the observation times, the former TIDs can be attributed to the straight tsunami from the mainshock, while the latter TIDs are most likely driven by tsunami from aftershocks. Furthermore, we also observed tsunami-like TIDs at about 11:50 UT with similar horizontal velocity and direction compared to tsunami waves. However, the arrival time of the TIDs was about 1.5 earlier than tsunami waves in the sea level and should be induced by other sources.
\end{abstract}

Keywords: GPS; Total electron content; Traveling ionospheric disturbances; Tsunami

\section{Background}

A tsunami is generated when a large oceanic earthquake or volcanic eruption causes a rapid displacement of the ocean floor. Tsunami detection by ionospheric monitoring is originated from the view indicated in Hines (1972) and Peltier and Hines (1976). The atmospheric gravity waves (AGWs) produced by tsunami can propagate obliquely in the atmosphere. During the upward propagation, the exponential decrease of the atmospheric density leads to significant increase of the gravity wave's amplitude due to the energy conservation law. The AGWs interact with the plasma at ionospheric height, leading to the generation of traveling ionospheric disturbances (TIDs). The tsunami-driven TIDs have similar propagation characteristics in terms of horizontal velocity, direction, period, and observation time compared to the tsunami waves causing them (Rolland et al. 2010).

After the devastating 2004 Indian Ocean Tsunami, scientific communities pay many interests on observing tsunami by ionospheric sounding (Artru et al. 2005; Liu et al. 2006; Occhipinti et al. 2006; Mai and Kiang 2009;

* Correspondence: xhzhang@sgg.whu.edu.cn

School of Geodesy and Geomatics, Wuhan University, Wuhan 430079, China
Hickey et al. 2010; Rolland et al. 2010; Galvan et al. 2011; Liu et al. 2011; Makela et al. 2011; Iyemori et al. 2013; Occhipinti et al. 2013). Due to the high spatial and temporal resolution, total electron content (TEC) derived from ground-based GPS has widely been used as the observations in the studies. The tsunami-driven TIDs are observed in ionosphere TEC after many tsunami events using ground-based GPS stations, suggesting that the ionosphere is sensitive to the tsunami waves and the ionospheric sounding has the potential application in tsunami warning. Although many scholars obtain a wealth of research results on the study of GPS ionospheric tsunami sounding, further research is necessary for more reasonable and comprehensive recognition of the issue, considering the complexity of real tsunami propagation.

The Tohoku (Japan) earthquake $(\mathrm{Mw}=9)$ occurred at 05:46 UT on 11 March 2011 and then triggered powerful tsunami. Several scholars used the near-field GEONET GPS data in Japan to analyze this event and observed the tsunami-induced TIDs in ionosphere TEC (Liu et al. 2011; Rolland et al. 2011; Tsugawa et al. 2011; Occhipinti et al. 2013). In this study, we apply the GPS 
TEC observations in Hawaii, which is far away from the epicenter, to detect the tsunami-driven TIDs after the 2011 Tohoku tsunami. Hawaii is located at the center of the Pacific Ocean that is very suitable for tsunami monitoring in the open sea.

\section{Methods}

The slant ionospheric TEC $s$ can be calculated from the geometry-free combination of GPS $L_{1}$ and $L_{2}$ carrier phases $\left(L_{4}=L_{1}-L_{2}\right)$ for each satellite-receiver pair:

$$
s=L_{4} / k+b
$$

where $k$ is the conversion factor between TEC and observation $(k \approx 0.105 \mathrm{~m} / \mathrm{TECU}) ; b$ is an unknown constant bias. Although Equation 1 cannot acquire the absolute value of TEC at a particular time, it can capture the TEC variation over time with high precision, which is important for TID detection.

In this paper, we employ a second-order numerical difference method to eliminate the diurnal variation and the bias in TEC (Tang and Zhang 2014). This method is very simple and beneficial to real-time application. Compared to the first-order numerical difference applied in Hernandez-Pajares et al. (2006), the second-order numerical difference can also effectively detrend the TEC series with lower satellite elevation angle which is meaningful for tsunami monitoring. The difference process is as follows:

$$
\begin{gathered}
\Delta s(t)=s(t)-0.5(s(t-\tau)+s(t+\tau)) \\
\Delta^{2} s(t)=\Delta s(t)-0.5(\Delta s(t-\tau)+\Delta s(t+\tau))
\end{gathered}
$$

where $t$ is the observation epoch; $\tau$ is the time step; $\Delta s(t)$ and $\Delta^{2} s(t)$ are the first-order and second-order difference series, respectively.

The second-order difference series and primitive TID signal have the same period $(T)$, and the ratio of amplitude is $4 \sin ^{4}(\pi \tau / T)$ (Tang and Zhang 2014). According to the expression, the correlation between the amplitude ratio and the TID period is plotted in Figure 1 with $\tau=300 \mathrm{~s}$. As shown in Figure 1, the sensitive period scope is 6 to $25 \mathrm{~min}$ with ratio bigger than 0.5 , which is suitable for the TID detection induced by the tsunami.

\section{Results and discussion}

The GPS observations in Hawaii are collected from the public website of UNAVCO (http://www.unavco.org/), and the locations of the stations are showing in Figure 2. The number of the ground-based stations is about 60 , and data sampling rate is $30 \mathrm{~s}$, which is enough to observe the TIDs induced by AGWs. A single-layer model with a height of $350 \mathrm{~km}$ is used to obtain the vertical TEC (vTEC) values and positions of ionospheric pierce

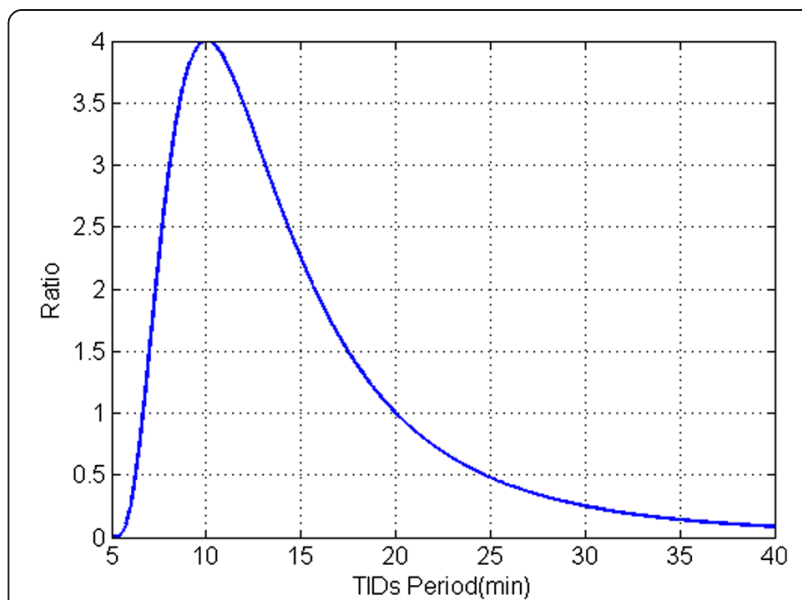

Figure 1 The ratio of the amplitude in term of TIDs' period. The time step is $300 \mathrm{~s}$ and the maximum ratio is 4 with a period of 10 min. TID, traveling ionospheric disturbance.

point (IPP). Then, we employ the second-order numerical difference method to extract the vTEC variation series.

In order to distinguish the tsunami-driven TIDs from the vTEC variation series, we plot the vTEC variations as a function of distance and time, namely, the time-distance map: the origin is the epicenter of the earthquake, the $X$ axis is the observation time, and the $Y$-axis is the distance between the IPP and the epicenter. Figure 3 shows the time-distance map of vTEC variations during different observation times. Considering that tsunami-driven TIDs have similar propagation characteristics as the tsunami causing them, an effective way to distinguish ionospheric

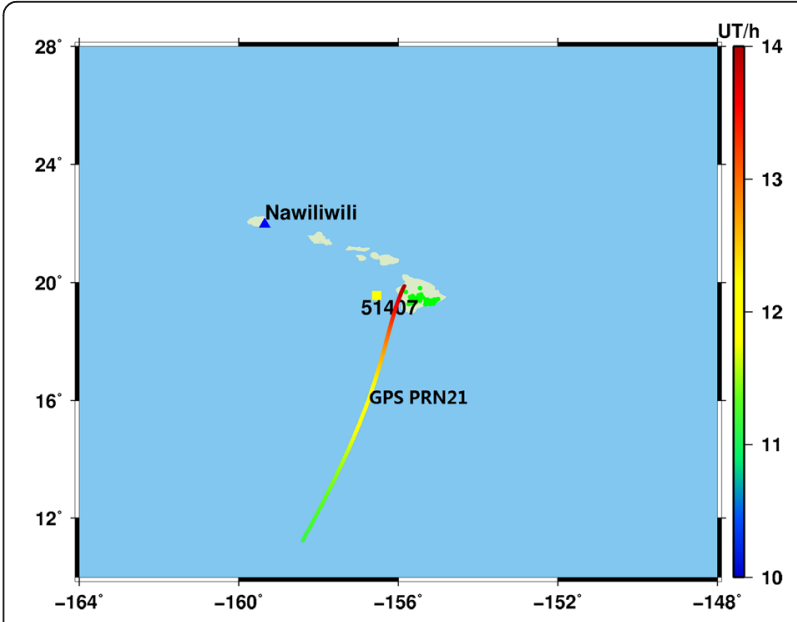

Figure $\mathbf{2}$ The locations of GPS ground stations and tsunami stations in Hawaii. The green dots indicate the GPS ground stations, the blue triangle notes the tide-gauge station, and the yellow square marks the DART station. 
signals associated with tsunami is to search for perturbations with horizontal velocity around $200 \mathrm{~m} / \mathrm{s}$ (the approximate speed of tsunami) and direction outward from the tsunami's source (Galvan et al. 2011).

As shown in Figure 3a, there are obvious tsunami-like TIDs with horizontal velocity of approximately $260 \mathrm{~m} / \mathrm{s}$ in an outward direction from the epicenter that appeared at about 11:50 UT, which is observed by GPS PRN 29. This horizontal velocity is similar to the tsunami speed over adjacent area, which can reach to $v=\sqrt{g h}=242 \mathrm{~m} / \mathrm{s}$ with a depth $(h)$ of $6 \mathrm{~km}$ and a gravity $(g)$ of $9.8 \mathrm{~m} / \mathrm{s}^{2}$. To examine the signal in the ionosphere, the sea-level tsunami measurements recorded by a coastal tide gauge in Nawiliwili and a DART buoy (51407) at adjacent area are plotted in Figure 4. As can be seen in Figure 4, the tide gauge and DART buoy firstly observed the tsunami waves at about 13:10 and 13:20 UT. As showing in Figure 2, the trajectory of GPS satellite PRN 21 is very close to the position of DART buoy (51407). Figure 5a shows the vTEC variation series derived from satellite PRN 21 using ground station AHUP. Comparing Figures $4 \mathrm{~b}$ and $5 \mathrm{a}$, we can see that the arrival time of the TIDs was about $1.5 \mathrm{~h}$ earlier than the tsunami waves in the sea level. Considering that the tsunami signals in the ionosphere and sea level should have similar arrival time, the TIDs observed at about 11:50 UT are not triggered by the tsunami from the mainshock.

Carefully examining Figure 3a, there are tsunami-like TIDs with a horizontal velocity of approximately $260 \mathrm{~m} / \mathrm{s}$ in an outward direction from the epicenter that occurred

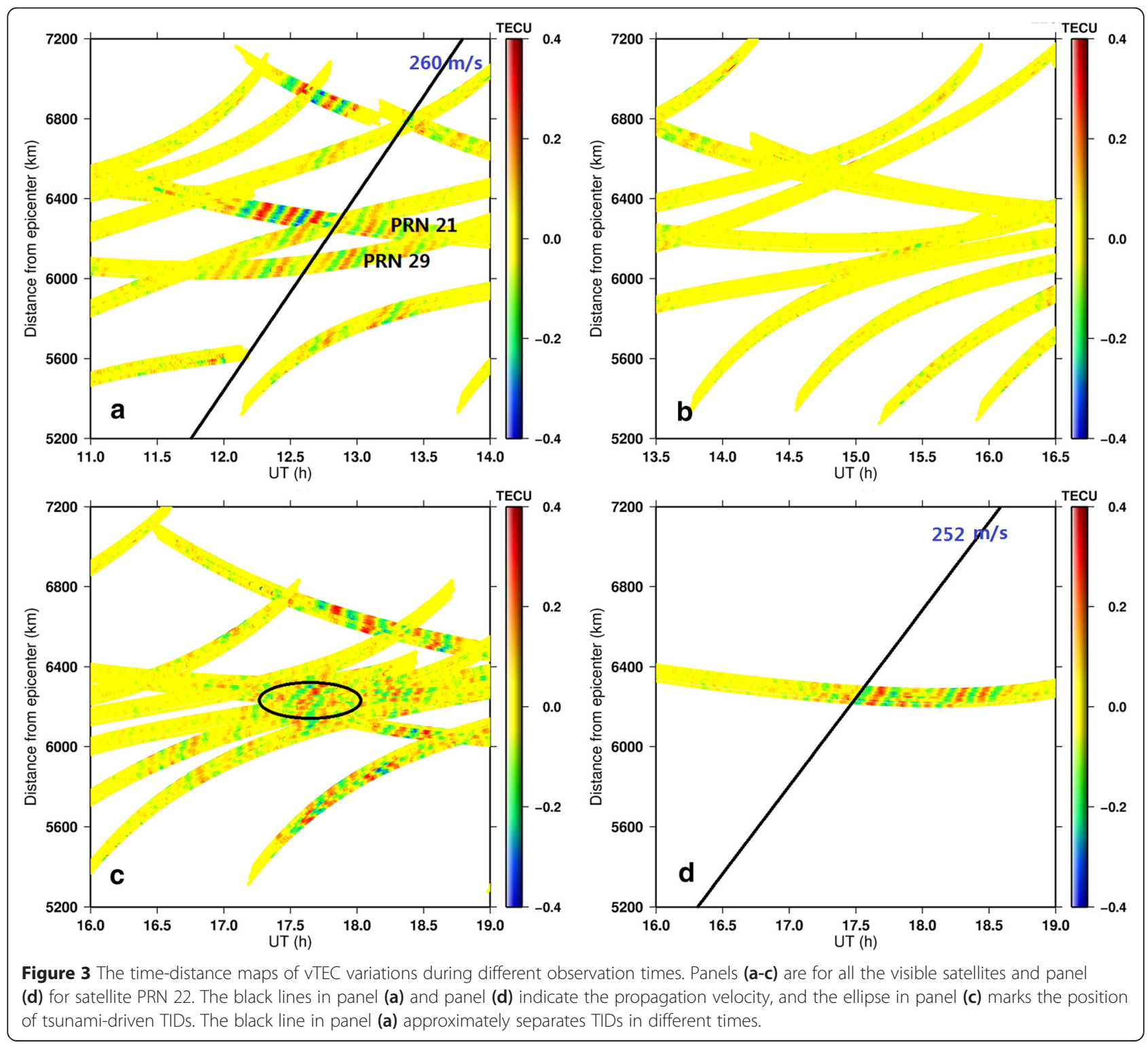



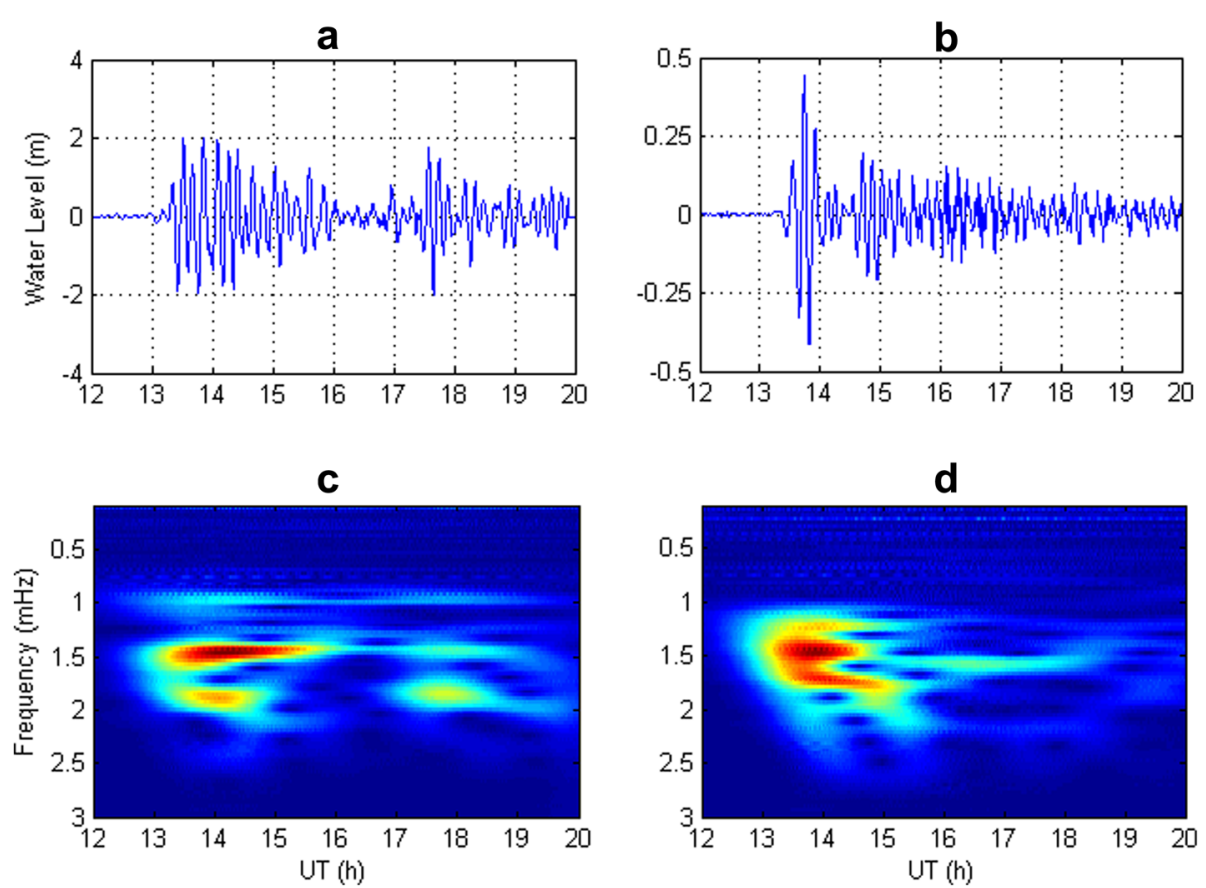

Figure 4 The sea-level tsunami series and time-frequency diagrams. Panel (a) is the coastal tide gauge in Nawiliwili, and panel (b) is the DART 51407 buoy. Panels (c) and (d) are corresponding time-frequency diagrams.
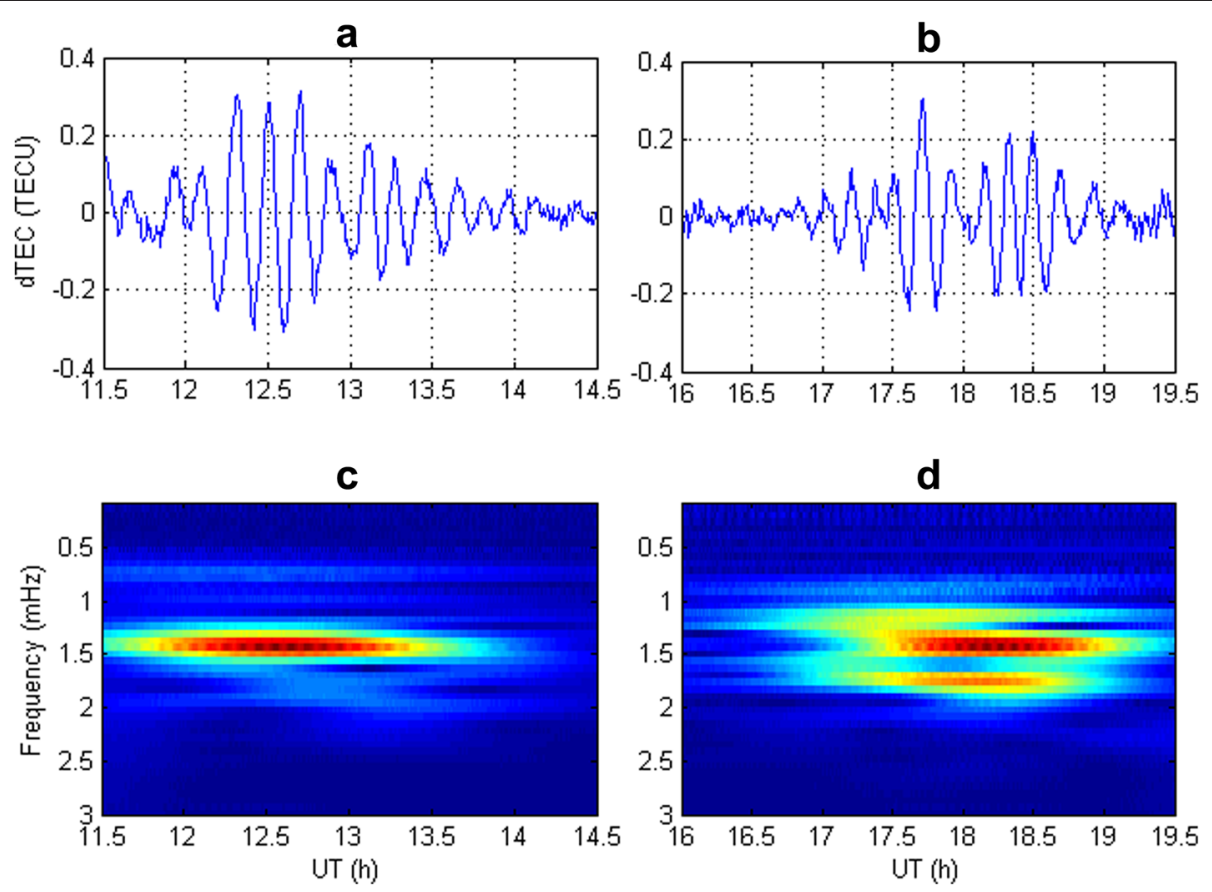

Figure 5 The VTEC variation series and time-frequency diagrams. The results are derived from satellite PRN 21 (panel (a)) and satellite PRN 22 (panel (b)) using the observations in station AHUP. Panels (c) and (d) are corresponding time-frequency diagrams. 
at about 12:40 UT observed by GPS PRN 29. Then, the TIDs were detected by GPS PRN 21 at about 13:00 UT. Different from the previous TIDs that appeared at about 11:50 UT, the arrival time of the TIDs is consistent to the tsunami waves in the sea level with only 20-min intervals (seen in Figures $4 \mathrm{~b}$ and $5 \mathrm{a}$ ). Figures $4 \mathrm{c}, \mathrm{d}$ and $5 \mathrm{c}$ also present the corresponding time-frequency diagrams for observed tsunami waves and ionospheric signals. The frequencies for tsunami waves during 13:00 to 15:00 UT are $1 \sim 2 \mathrm{mHz}$ centered $1.42 \mathrm{mHz}$ (period about $12 \mathrm{~min}$ ). The center frequency is also $1.42 \mathrm{mHz}$ for the vTEC variation series during this period, suggesting that the period of TIDs is similar to the tsunami waves as well. Based on the similar horizontal velocity, direction, arrival time, and period, the observed TIDs that appeared about 12:40 UT in the ionosphere are confirmed induced by tsunami waves.

As can be seen in Figure 3, the TID signals began to weaken and gradually disappeared after 14:00 UT. Furthermore, the water level of tsunami waves also decreased after 15:00 UT as shown in Figure 4. This indicates that the tsunami waves were over the Hawaii area and propagated to more remote areas. However, the amplitudes of vTEC variations began to increase at about 16:30 UT (see Figures $3 \mathrm{c}$ and $5 \mathrm{~b}$ ). This can be attributed to the diurnal variation of plasma density in the ionosphere increasing from night to day (the local time is about 06:00). During the period of sunrise or sunset, the energy in the atmosphere varies drastically and leads to the instability of the atmosphere, which might induce the ionospheric disturbances (Somsikov 1995).

As shown in Figure 3c, there were tsunami-like TIDs with horizontal velocity of approximately $250 \mathrm{~m} / \mathrm{s}$ in an outward direction from the epicenter that appeared again at about 17:30 UT. Due to the superposition of vTEC variations, the signals are not very clear. To see more clearly, we use the ellipse mark of the position of tsunami-driven TIDs in Figure $3 \mathrm{c}$ and plot the timedistance map separately for satellite PRN 22 in Figure 3d. As discussed above, the horizontal velocity of the tsunamidriven TIDs is also similar to tsunami speed over adjacent area. Furthermore, the water level increased significantly at about 17:30 UT recorded by the tide gauge (see Figure 4a), indicating the arrival of tsunami waves. This means that the observation time between tsunami-like TIDs and tsunami waves is consistent. It should be noted that the DART buoy did not record the increased water level at similar time. The reason may be that the tsunami waves did not pass the region near the buoy.

Similarly, to compare the period between the detected TIDs and the tsunami waves, the vTEC variation series derived from satellite PRN 22 using the observations in station AHUP and corresponding time-frequency diagram are also plotted in Figure 5. As can be seen in Figures $4 \mathrm{c}$ and $5 \mathrm{~d}$, both of the TIDs and tsunami waves have center frequencies of 1.42 and $1.75 \mathrm{mHz}$ (period about $9.5 \mathrm{~min}$ ), respectively, during 17:00 to 19:00 UT, indicating that they have similar periods. To remove possible recurrent TIDs, we also process the data on the same time before and after the event day and do not observe similar results. As shown in Figure 6, the disturbance velocities are about 1,500 and $900 \mathrm{~m} / \mathrm{s}$ on the day before and after the event day, respectively, during 17:30 18:00 UT, which is far larger than the tsunami velocity. So, it can also be confirmed that the observed TIDs that appeared about 17:30 UT in the ionosphere

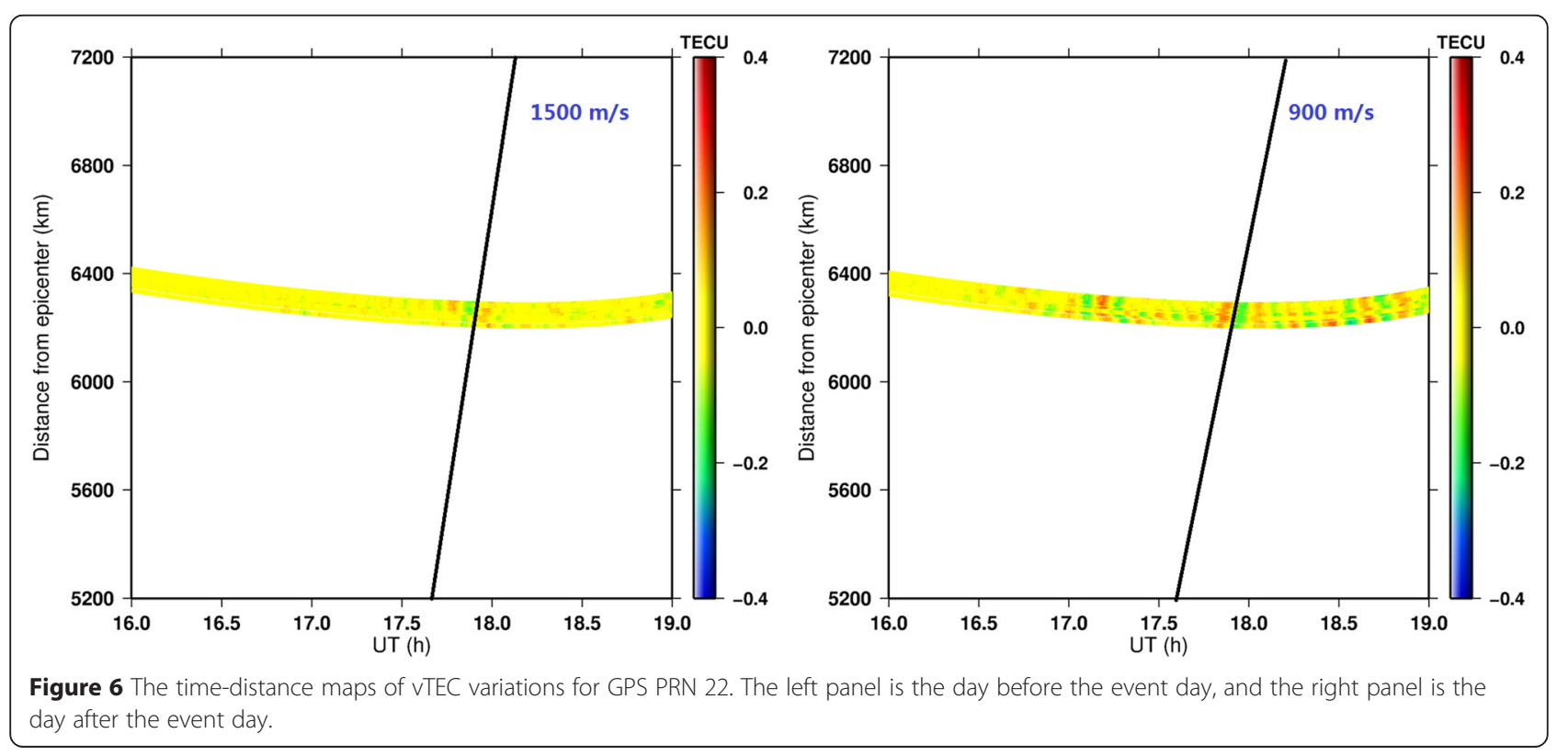


Table 1 The propagation characteristics for observed TIDs

\begin{tabular}{llll}
\hline TIDs & $\boldsymbol{T}(\mathbf{U T})$ & $\boldsymbol{v}_{\boldsymbol{h}}(\mathbf{m} / \mathbf{s})$ & $\boldsymbol{A}_{\boldsymbol{z}}\left(^{\circ}\right)$ \\
\hline 1 & $11: 50$ & 263.18 & 132.60 \\
2 & $12: 40$ & 244.67 & 126.87 \\
3 & $17: 30$ & 244.54 & 112.68 \\
\hline \multicolumn{2}{l}{ The expressions $T, v_{h}$ and $A_{\boldsymbol{z}}$ represent the arrival time, horizontal velocity, and } \\
azimuth, respectively. TID, traveling ionospheric disturbance.
\end{tabular}

on the event day were triggered by the tsunami in view of their similar propagation characteristics in terms of horizontal velocity, direction, period, and observation time.

To obtain more reliable results, the propagation characteristics for all observed TIDs are estimated (Wang et al. 2007; Zhang et al. 2013), and the results are listed in Table 1 . The basic processes for the estimation method are as follows: 1) extract the Fourier coefficient complex phase differences (time delay in the frequency domain) between the TEC variation series observed at least three stations by Fourier transform; 2) assuming the TIDs are planar waves, the wave numbers in the $X$-axis (pointing to the east direction) and $Y$-axis (pointing to the north direction) can be solved according to the coordinates of stations and the phase differences; and 3) estimate the horizontal velocity and azimuth of the TIDs according to the horizontal wave numbers. As seen from the table, the horizontal velocities for the TIDs that appeared at about 12:40 and 17:30 UT are all about $244 \mathrm{~m} / \mathrm{s}$, which are very close to the tsunami velocity at the adjacent area, confirming that they are triggered by the tsunami waves.

The above observations show that the tsunami-driven TIDs appeared at different times: the former TIDs were observed at about 12:40 UT and the latter TIDs at about 17:30 UT. According to the observation time, the tsunami waves that induced the former TIDs can be attributed to the mainshock. As mentioned above, the tide gauge and DART buoy recorded significant amplitudes of the tsunami waves. They began at about 13:00 UT and then gradually decreased after 15:00 UT suggesting the lack of energy. However, another group of tsunami waves with larger amplitudes that triggered the latter TIDs appeared again at about 17:30 UT. Considering the similar propagation direction to tsunami waves observed at about 17:30 UT, the possible cause leading to the latter tsunami waves might be the aftershocks. According to the records, there were several aftershocks $\left(M_{w}>6.5\right)$ near the epicenter of mainshock within $5 \mathrm{~h}$ that might trigger new tsunami.

\section{Conclusions}

In this paper, we use the far-field ionospheric TEC derived from ground-based GPS observations in Hawaii to detect the TIDs triggered by the 2011 Tohoku tsunami.
The tsunami-driven TIDs had similar propagation characteristics in terms of horizontal velocity, direction, period, and observation time compared to the tsunami waves causing them, confirming again that the ionosphere is sensitive to the tsunami waves. These tsunami-driven TIDs appeared at different times: the former TIDs are observed at about 12:40 UT and disappeared at about 14:00 UT, and then, the latter TIDs appeared at about 17:30 UT. This is the first time we observed the phenomenon. The former TIDs can be attributed to the straight tsunami from the mainshock just like previous literatures, while the latter TIDs are most likely driven by tsunami from aftershocks. Furthermore, we also observed tsunami-like TIDs at about 11:50 UT with similar horizontal velocity and direction but different arrival time compared to tsunami waves in the sea level, suggesting that they may be induced by other sources.

The results supply a new case showing that the tsunami can trigger the TIDs. More importantly, the observation results indicate that the straight tsunami from the mainshock might not be the only source to induce the disturbances. This study provides a new recognition of tsunami-driven TIDs and support for the future tsunami-warning system.

\section{Competing interests}

The authors declare that they have no competing interests.

\section{Authors' contributions}

LT and XZ conceived and designed the experiments; LT and ZL performed the experiments and analyzed the data; and LT wrote the manuscript. All authors read and approved the final manuscript.

\section{Acknowledgements}

The GPS data used in this study are provided by the Plate Boundary Observatory operated by UNAVCO for EarthScope (www.unavco.org/). The DART data and tide data are provided by the National Data Buoy Center (NDBC) and Center for Operational Oceanographic Products and Services (CO-OPS) of the National Oceanic and Atmospheric Administration. This study was supported by the National Natural Science Foundation of China (Grant No. 41474025, No. 41204030), Fundamental Research Funds for the Central Universities (Grant No. 2014214020201), and the Surveying and Mapping Foundation Research Fund Program, National Administration of Surveying, Mapping and Geoinformation (13-02-07).

Received: 30 January 2015 Accepted: 22 April 2015

Published online: 11 June 2015

\section{References}

Artru J, Ducic V, Kanamori H, Lognonné P, Murakami M (2005) lonospheric detection of gravity waves induced by tsunamis. Geophys J Int 160:840-848

Galvan DA, Komjathy A, Hickey MP, Mannucci AJ (2011) The 2009 Samoa and 2010 Chile tsunamis as observed in the ionosphere using GPS total electron content. J Geophys Res 116:A06318, doi:10.1029/2010JA016204

Hernandez-Pajares M, Juan JM, Sanz J (2006) Medium-scale traveling ionospheric disturbances affecting GPS measurements: spatial and temporal analysis. J Geophys Res 111:A07S11, doi:10.1029/2005JA011474

Hickey MP, Schubert G, Walterscheid RL (2010) Atmospheric airglow fluctuations due to a tsunami-driven gravity wave disturbance. J Geophys Res 115:A06308, doi:10.1029/2009JA014977

Hines CO (1972) Gravity waves in the atmosphere. Nature 239:73-78, doi:10.1038/239073a0

lyemori T, Tanaka Y, Odagi Y, Yasuharu S, Masahiko T, Masahito N, Mitsuru U, Domingo R, Edwin C, Jose I, Sadato Y, Kunihito N, Mitsuru M, Hiroyuki S (2013) Barometric and magnetic observations of vertical acoustic resonance 
and resultant generation of field-aligned current associated with earthquakes. Earth Planets Space 65:901-909

Liu JY, Tsai YB, Ma KF, Chen YK, Tsai HF, Lin CH, Kamogawa M, Lee CP (2006) Ionospheric GPS total electron content (TEC) disturbances triggered by the 26 December 2004 Indian Ocean tsunami. J Geophys Res 111:A05303, doi:10.1029 /2005JA011200

Liu JY, Chen CH, Lin CH, Tsai HF, Chen CF, Kamogawa M (2011) lonospheric disturbances triggered by the 11 March 2011 M9.0 Tohoku earthquake. J Geophys Res 116:A06319, doi:10.1029/2011JA016761

Mai CL, Kiang JF (2009) Modeling of ionospheric perturbation by 2004 Sumatra tsunami. Radio Sci 44:RS3011, doi:10.1029/2008RS004060

Makela JJ, Lognonné P, Hébert H, Gehrels T, Rolland L, Allgeyer S, Kherani A, Occhipinti G, Astafyeva E, Coïsson P, Loevenbruck A, Clévédé E, Kelley MC Lamouroux J (2011) Imaging and modeling the ionospheric airglow response over Hawaii to the tsunami generated by the Tohoku earthquake of 11 March 2011. Geophys Res Lett 38:LO0G02, doi:10.1029/2011GL047860

Occhipinti G, Lognonné KEA, Hebert H (2006) Three-dimensional waveform modeling of ionospheric signature induced by the 2004 Sumatra tsunami. Geophys Res Lett 33:L20104, do::10.1029/2006GL026865

Occhipinti G, Rolland L, Lognonné P, Watada S (2013) From Sumatra 2004 to Tohoku-Oki 2011: the systematic GPS detection of the ionospheric signature induced by tsunamigenic earthquakes. J Geophys Res 118:3626-3636, doi:10.1002/jgra.50322

Peltier WR, Hines CO (1976) On the possible detection of tsunamis by a monitoring of the ionosphere. J Geophys Res 81:1995-2000, doi:10.1029/JC081i012p01995

Rolland LM, Occhipinti G, Lognonné P, Loevenbruck A (2010) lonospheric gravity waves detected offshore Hawaii after tsunamis. Geophys Res Lett 37:L17101, doi:10.1029/2010GL044479

Rolland LM, Lognonné P, Astafyeva E, Kherani EA, Kobayashi N, Mann M, Munekane $H$ (2011) The resonant response of the ionosphere imaged after the 2011 off the Pacific coast of Tohoku Earthquake. Earth Planets Space 63:853-857

Somsikov VM (1995) On mechanisms for the formation of atmospheric irregularities in the solar terminator region. J Atmos Terr Phys 57:75-83

Tang L, Zhang X-H (2014) A multi-step multi-order numerical difference method for traveling ionospheric disturbances detection. In: China Satellite Navigation Conference (CSNC) 2014 Proceedings: Volume II. Springer, Berlin Heidelberg, pp 331-340, doi:10.1007/978-3-642-54743-0_27

Tsugawa T, Saito A, Otsuka Y, Nishioka M, Maruyama T, Kato H, Nagatsuma T, Murata KT (2011) Ionospheric disturbances detected by GPS total electron content observation after the 2011 off the Pacific coast of Tohoku Earthquake. Earth Planets Space 63:875-879

Wang M, Ding F, Wan W-X, Ning B-Q, Zhao B-Q (2007) Monitoring global traveling ionospheric disturbances using the worldwide GPS network during the October 2003 storms. Earth Planets Space 59:407-419

Zhang X-H, Tang L, Guo B-F (2013) Research on medium-scale traveling ionospheric disturbances using a modified SRTI method. Chin J Geophys 56:3953-3959, doi:10.6038/cjg20131201

\section{Submit your manuscript to a SpringerOpen ${ }^{\circ}$ journal and benefit from:}

- Convenient online submission

- Rigorous peer review

- Immediate publication on acceptance

- Open access: articles freely available online

- High visibility within the field

- Retaining the copyright to your article

Submit your next manuscript at $\gg$ springeropen.com 